\title{
ESTUDO DA INFLUÊNCIA DO PRÉ-TRATAMENTO ULTRASSÔNICO SOBRE A TRANSFERÊNCIA DE MASSA NOS PROCESSOS DE LIOFILIZAÇÃO E REIDRATAÇÃO DE JACA (Artocarpus heterophyllus)
}

\author{
D. S. ANDRADE*, R. J. BRANDÃO, L. G. MARQUES, M. M. PRADO \\ Universidade Federal de Sergipe, Departamento de Engenharia Química \\ *e-mail: douglasandrade.eng @gmail.com
}

\begin{abstract}
RESUMO
A liofilização é uma técnica de alto custo, havendo a necessidade de ser assistida por outras técnicas ou pré-tratamentos que reduzam o tempo de processamento, minimizando, assim, os custos. Logo, o objetivo deste trabalho foi avaliar a influência do pré-tratamento ultrassônico sobre a cinética de liofilização de jaca, bem como sobre as características de reidratação e de cor do produto. Antes do início do processo, o material foi submetido a um banho ultrassônico, com frequências de 25 e $40 \mathrm{kHz}$, e tempos de exposição de 3 e 10 min. O processo de liofilização foi conduzido a $98 \mu \mathrm{mHg}$ e a $-50^{\circ} \mathrm{C}$. Ao contrário do esperado, o pré-tratamento ultrassônico não intensificou as taxas de transferência de massa envolvidas nos processos de liofilização e reidratação. A difusividade efetiva na secagem nas amostras sonicadas foi reduzida de 8 a $16 \%$, comparada a amostra sem tratamento. $\mathrm{O}$ uso do pré-tratamento ultrassônico reduziu a capacidade de reidratação na saturação em até $28 \%$, aumentando ainda a perda de sólidos solúveis em $12 \%$. A luminosidade dos frutículos de jaca, sonicados ou não, foi melhorada após a secagem, conforme evidenciado pelo aumento dos valores de $\mathrm{L}^{*}$.
\end{abstract}

\section{INTRODUÇÃO}

A jaca pertence à família Moraceae e ao gênero Artocarpus. É um fruto originário da Ásia (Índia, Malásia, Filipinas), que foi introduzido e difundido no Brasil pelos portugueses no século XVIII e adaptou-se muito bem. Há três variedades da jaca: Jacadura, que possui os maiores frutos, variando de 15 a $40 \mathrm{~kg}$, com bagos de consistência rígida, utilizadas para a produção de $\operatorname{compotas}^{1}$; Jacamole, com frutos menores, bagos doces e moles, contendo menos látex do que as outras e a Jaca-manteiga, apresentando bagos bem adocicados e de consistência intermediária, sendo comumente encontrada no estado do Rio de Janeiro e muito confundida com a Jaca- mole (OLIVEIRA, GODOY e BORGES, 2009).

A jaca é uma fruta sazonal, seu consumo é feito em quase sua totalidade sob a forma "in natura" e é realizado nos meses de janeiro a abril, no Nordeste, razão pela qual, nos meses restantes, necessitam-se de tecnologias que preservem ou transformem o fruto fresco para consumo. Isso se deve a alta perecibilidade do fruto, que faz com que sua preservação somente seja possível por um curto período de tempo após a colheita (DUARTE, UGULINO, et al., 2012).

As frutas são utilizadas nas práticas de boa alimentação, a fim de ter uma boa saúde. Para tanto, elas devem estar inseridas em nossa

\footnotetext{
${ }^{1}$ Conserva de frutas.
} 
dieta diária. Elas apresentam uma alta porcentagem de água, podendo chegar aos $95 \%$, têm poucas calorias e são ricas em vitaminas e minerais, ajudando, portanto, a prevenir doenças (SILVA, TREVISANI, et al., 2005).

Na desidratação, que tem como objetivo reduzir o elevado teor de umidade para se ter uma alta durabilidade, existem alguns fatores inerentes ao material que influenciam o processo, como a morfologia das frutas (composição do tecido vegetal) e a capacidade que elas têm de armazenar água no interior de suas células, devido às organelas existentes nelas.

A liofilização, dentre os inúmeros processos de secagem, é diferenciada por permitir a obtenção de produtos com maior qualidade.

Os produtos liofilizados possuem algumas vantagens em relação àqueles desidratados por meio de outras técnicas, como uma reidratação mais rápida, uma maior retenção de características nutricionais e organolépticas, devido à baixa temperatura operacional, que contribui para minimizar a perda de componentes voláteis (FISSORE, PISANO e BARRESI, 2013). Há também uma boa preservação da aparência e da cor dos produtos, sem a necessidade do uso de aditivos. O tempo para tais produtos perecerem é prolongado, com a redução da massa, o custo com transporte e estocagem é reduzido e a perda de nutrientes, no caso dos alimentos, é insignificante (ZHANG HUA, YANG XIN, et al., 2014).

A liofilização é considerada uma técnica de alto custo, tendo-se a necessidade da adição de técnicas que reduzam o tempo de processamento, visando a redução de custos. A aplicação de ondas ultrassônicas em processos de secagem induz ao aparecimento de variação de pressão nas interfaces sólido/gás, além de aumentar a taxa de evaporação na superfície. Este efeito é causado pela formação de fissuras que afetam diretamente a camada limite de difusão. Desta maneira, verifica-se que a utilização de pré-tratamentos ultrassônicos afeta a estrutura do material, que influenciará tanto no processo de secagem do material quanto na sua capacidade de reidratação (MASON, 1998).

O objetivo deste trabalho foi avaliar a influência do pré-tratamento ultrassônico sobre a cinética de liofilização de frutículos de jaca (Artocarpus heterophyllus), bem como sobre as características de reidratação e atributos de cor do produto.

\section{MATERIAIS E MÉTODOS}

Os estudos foram realizados no Laboratório de Fenômenos de Transporte em Sistemas Particulados do Departamento de Engenharia Química e no Laboratório de Análise de Compostos Orgânicos Poluentes do Departamento de Química da Universidade Federal de Sergipe.

\subsection{Materiais}

O material utilizado neste trabalho consistiu de frutículos de jaca-dura, em estádio de maturação, adquiridos no mercado municipal de Aracaju.

\subsection{Metodologia experimental}

\subsubsection{Caracterização do material}

Os frutículos da jaca foram cortados em formato de uma placa, medindo-se, através do paquímetro digital (Digimess $-10^{-2} \mathrm{~mm}$ ), os valores de comprimento, largura e espessura das amostras, com o cuidado de que a espessura fosse significativamente menor que as outras duas dimensões, a fim de considerar transferência de massa unidimensional. Ao fim do corte, as massas das amostras de jaca foram aferidas numa balança semianalítica (Marte UX420H, Shimadzu) com precisão de $10^{-6} \mathrm{~kg}$. 


\subsubsection{Pré-tratamento Ultrassônico}

As amostras caracterizadas foram dispostas em béqueres de $500 \mathrm{ml}$, preenchidos com água destilada, e introduzidos num banho ultrassônico (UltraSonic Cleaner, Unique). Foram utilizadas quatro condições diferentes para esse tratamento; são elas: (a) frequência de $25 \mathrm{kHz}$ durante 3 minutos, (b) $25 \mathrm{kHz}$ em 10 minutos, (c) $40 \mathrm{kHz}$ em 3 minutos e (d) 40 $\mathrm{kHz}$ em 10 minutos.

\subsubsection{Liofilização}

As amostras, devidamente armazenadas no congelador, em placas de Petri, foram retiradas. Junto com as amostras pré-tratadas, também foram armazenadas aquelas que não foram imersas no banho ultrassônico, chamadas amostras Controle.

O liofilizador (Liobras L101, Liotop) foi ligado e, ao atingir a temperatura de, aproximadamente, $-50^{\circ} \mathrm{C}$, as amostras foram retiradas do congelador e inseridas rapidamente nas prateleiras, presentes no interior da câmara de acrílico do liofilizador. A bomba de vácuo foi, então, ligada. A partir desse momento, o processo de liofilização teve início, com o valor de pressão, mostrado no painel, atingindo a marca de $98 \mu \mathrm{mHg}$.

Em tempos pré-determinados, a bomba era desligada, as amostras eram retiradas do liofilizador e pesadas na balança. Logo após, as mesmas eram colocadas de volta no equipamento, dando-se continuidade ao processo. A partir da constatação de que a massa não mais variava significativamente com o tempo, o processo de secagem foi interrompido e o equipamento desligado.

\subsubsection{Reidratação}

Após as amostras serem liofilizadas, fezse a reidratação das mesmas. Com o uso de um béquer preenchido com água destilada, à temperatura ambiente, inseriu-se a amostra e, de tempos em tempos, a mesma era retirada do béquer, com o excesso de água sendo removido com o auxílio de papel toalha, para a aferição de sua massa. Esse procedimento foi repetido até que a massa da amostra não mais variasse com o tempo, ou quando começasse a perder massa, indicando que a estrutura da fruta havia sido danificada. A cinética de reidratação foi analisada em termos da evolução ao longo do tempo do processo da razão de reidratação (RR), definida como:

$$
\text { R.R. }=\frac{X_{(t)}}{X_{0}}
$$

Foram calculados também os índices de reidratação de Lewick, que são: capacidade de absorção de água (CAA), capacidade de retenção de massa seca $\left(\mathrm{CRM}_{\mathrm{s}}\right)$ e a capacidade de reidratação (CR).

$\mathrm{O}$ índice CAA fornece informação sobre a capacidade de absorção de água do material seco:

$$
C A A=\frac{m_{r h}\left(100-S_{r h}\right)-m_{d}\left(100-S_{d}\right)}{m_{0}\left(100-S_{0}\right)-m_{d}\left(100-S_{d}\right)}
$$

Sendo $m$ a massa, $S$ o teor de sólido seco e os subscritos $0, d$ e $r h$ referem-se à amostra fresca, desidratada e reidratada, respectivamente. $\mathrm{O}$ índice varia de 0 a 1 . Quanto menor o índice, a capacidade de absorver água por parte da fruta fica mais prejudicada, impossibilitando a mesma de atingir o teor de umidade próximo da amostra fresca, evidenciando que o processo influenciou a estrutura do material.

$\mathrm{O}$ índice $\mathrm{CRM}_{\mathrm{s}}$ mensura a perda de massa seca durante a reidratação, expressando a habilidade do material em reter sólidos solúveis.

$$
\mathrm{CRM}_{\mathrm{s}}=\frac{\mathrm{m}_{\mathrm{rh}} \mathrm{S}_{\mathrm{rh}}}{\mathrm{m}_{\mathrm{d}} \mathrm{S}_{\mathrm{d}}}
$$

O índice também varia de 0 a 1 . Quanto mais o tecido da fruta é danificado, menor é o 
índice, pois maior é a lixiviação de sólidos durante a reidratação.

Finalmente, a capacidade de reidratação se baseia na capacidade do material em absorver água e reter sólidos solúveis. Quanto maior o dano sofrido pela amostra, menor o índice.

$$
\mathrm{CR}=\mathrm{CAA}^{\mathrm{CRM}} \mathrm{s}_{\mathrm{s}}
$$

\subsubsection{Colorimetria}

Os ensaios colorimétricos foram realizados em um espectrofotômetro portátil HunterLab, modelo Miniscan EZ, iluminante primário D65, ângulo de observação de $10^{\circ}$ e abertura da célula de medida de $30 \mathrm{~mm}$. As condições experimentais foram padronizadas para a emissão e detecção do feixe de luz. O espaço cromático utilizado foi o CIE (Comission International de I'Eclairage) $\mathrm{L}^{*} \mathrm{a}^{*} \mathrm{~b}^{*}$, onde $\mathrm{L}^{*}$ representa a luminosidade, $a^{*}$ a cor vermelha ou verde, e b* amarelo ou azul.

O ensaio de cor foi feito antes das amostras serem colocadas no liofilizador e após o término do processo, a fim de analisar as alterações dos parâmetros de cor do produto liofilizado. Três tomadas de cor para cada amostra foram realizadas, fazendo, após, a média das três medidas para cada condição de tratamento.

A partir dos valores dos parâmetros $\mathrm{L}^{*}$, $a^{*}$ e $b^{*}$, o ângulo hue e o croma foram calculados de acordo com as equações (CHUNTHAWORN, ACHARIYAVIRIYA, et al., 2012):

$$
\begin{aligned}
& \text { hue }=\tan ^{-1}(\mathrm{~b} * / \mathrm{a} *) \\
& \text { croma }=\left(\mathrm{a} *^{2}+\mathrm{b} *^{2}\right)^{1 / 2}
\end{aligned}
$$

Chroma indica a pureza ou saturação da cor e o ângulo hue que expressa a mudança de coloração $\left(0^{\circ}\right.$ ou $360^{\circ}$ representa hue vermelho, enquanto ângulos de 90, 180 e 270
${ }^{\circ} \mathrm{C}$ indicam amarelo, verde e azul, respectivamente).

\subsubsection{Umidade}

A determinação de umidade dos frutículos de jaca "in natura", liofilizados e reidratados foi realizada pelo método de secagem em estufa (AL 102/42, AmericanLab) a $(105 \pm 3)^{\circ} \mathrm{C}$ por 24 horas, até a partir da obtenção da massa de sólido seco, conforme recomendado pela norma $\mathrm{n}^{\circ} 4.5 .1$ do Instituto Adolfo Lutz (LUTZ, 1985).

\subsection{Tratamento e Análise dos Dados}

A partir dos resultados obtidos nos experimentos de secagem, as curvas que representam a cinética foram traçadas, relacionando o adimensional de umidade (X.R.) em função do tempo de processamento.

Para representar a cinética de liofilização da jaca, utilizou-se no presente trabalho o modelo difusivo. Para tanto, as seguintes hipóteses foram adotadas:

- Transferência de massa unidimensional e predominantemente difusiva.

- O teor de umidade na superfície da partícula atinge instantaneamente o valor de equilíbrio (X.e.);

- Sistema com encolhimento negligenciável.

- Processo isotérmico com a difusividade mássica independente da umidade. unicial;

-Distribuição uniforme de umidade

A solução aproximada, truncada no primeiro termo da série, é expressa da seguinte forma:

$$
X R=\frac{X-X_{e}}{X_{0}-X_{e}}=\operatorname{arexp}\left[-D_{\text {eff }} \cdot\left(\frac{t}{L_{c}^{2}}\right)\right]
$$


Para descrever a cinética de reidratação, foi utilizada a Equação de Weibull:

$$
\mathrm{RR}=\mathrm{RR}_{\mathrm{e}}-\left(1-\mathrm{RR}_{\mathrm{e}}\right) \exp \left[-\frac{\mathrm{t}}{\beta}\right]^{\alpha}
$$

A estimação dos parâmetros das Equações (7) e (8) foi feita via regressão nãolinear pelo método dos mínimos quadrados utilizando o software Statistica $8^{\circledR}$.A qualidade dos ajustes foi avaliada com base no coeficiente de correlação $\mathrm{R}^{2}$.

\section{RESULTADOS E DISCUSSÕES}

A partir dos dados obtidos nos experimentos, foi possível traçar curvas para determinar o comportamento cinético de secagem das amostras, com e sem prétratamento ultrassônico.

$\mathrm{Na}$ Figura 1 são apresentados os resultados típicos do adimensional de umidade em função do tempo.

Figura 1 - Adimensional de umidade em função do tempo de liofilização dos frutículos de jaca, com e sem pré-tratamento ultrassônico.

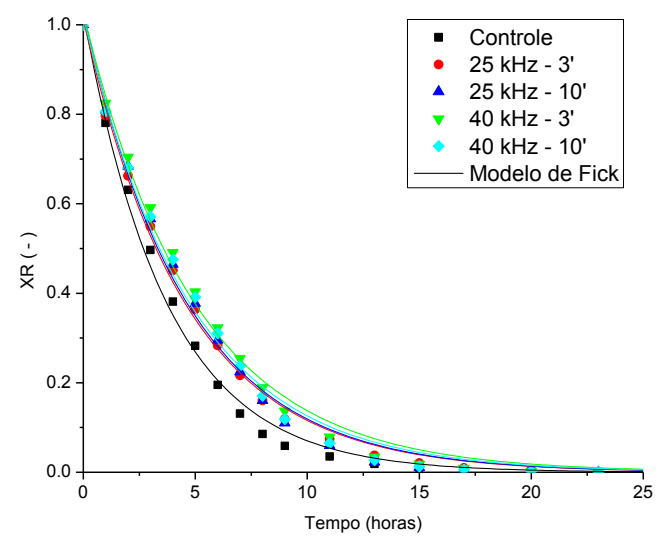

A partir da Figura 1Erro! Fonte de referência não encontrada., observa-se que não houve a influência do pré-tratamento ultrassônico no processo de liofilização da jaca. A maior remoção de umidade em menor tempo do processo foi na ausência do prétratamento, ou seja, para a amostra-controle.

$\mathrm{Na}$ Figura 2 são mostrados os resultados de taxa de liofilização em função do teor de umidade.

Figura 2 - Taxa de secagem em função do teor de umidade em base seca, na liofilização de frutículos de jaca com e sem pré-tratamento ultrassônico.

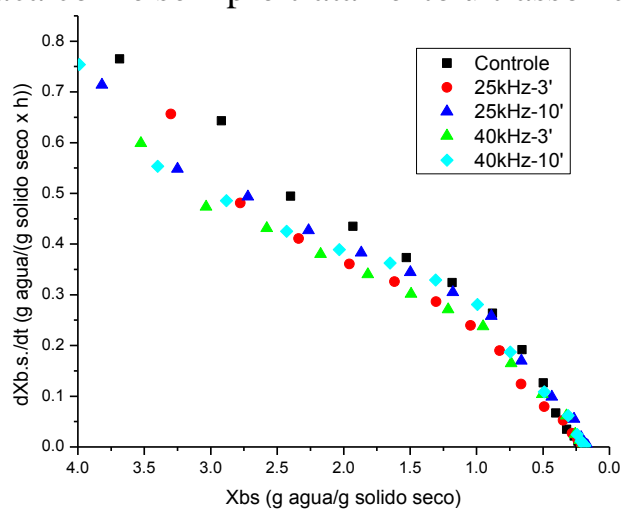

Pode ser constatado, com base na Figura 2, que o pré-tratamento com ultrassom não contribuiu para intensificar as taxas de transferência de massa na liofilização de frutículos de jaca.

Uma possível explicação pode ser o fato de que a aplicação do ultrassom, ao invés de fazer com que as fibras e poros da fruta ficassem espaçados, fez com que ficassem aglutinados, aumentando, assim, a resistência a transferência de umidade.

As maiores taxas foram apresentadas pela amostra-controle, sem pré-tratamento. No que diz respeito às amostras sonicadas, apesar de não haver uma diferença significativa entre as taxas de secagem obtidas, há uma ligeira tendência de aumento nas taxas de remoção de umidade quanto maior for o tempo das amostras no banho ultrassônico.

Independentemente do tipo de amostra, com a redução da umidade ao longo do tempo, a taxa de secagem diminui, como esperado. À medida que ocorre o avanço da frente de sublimação, a espessura da camada seca aumenta, o que torna mais difícil a transferência de vapor d'água pela camada 
seca. Além do mais, com a remoção de água dos poros, o espaço "vazio" vai sendo substituído pelo ar, o que também explica a redução na taxa de secagem, já que a condutividade térmica da água é cerca de 95 vezes maior que a do ar (PERRY et al, 2008).

Ainda de acordo com a Erro! Fonte de referência não encontrada. verifica-se que a liofilização da jaca, tanto para a amostracontrole como para as amostras pré-tratadas com ultrassom, ocorreu somente no período de taxa decrescente. O comportamento de secagem pode então ser explicado com base na teoria difusional, que se apoia exclusivamente sobre a lei de Fick, de modo que as resistências internas associadas à estrutura da fruta governam o fenômeno de transferência de massa.

Os dados da cinética de secagem foram então analisados com base no modelo difusivo, cujos parâmetros estimados da solução simplificada são apresentados na Tabela 1 .

Tabela 1 - Parâmetros estimados do modelo difusivo para a descrição da cinética de liofilização da jaca.

\begin{tabular}{lcccc}
\hline Tratamento & $\bar{L}_{C}(\mathrm{~mm})$ & $\begin{array}{l}\mathrm{D}_{\text {eff }} \\
\text { x 109 } \\
\left(\mathrm{m}^{2} / \mathrm{s}\right)\end{array}$ & $\mathrm{a} \mathrm{(-)}$ & $\mathrm{R}^{2}$ \\
\hline Controle & 7,952 & 4,672 & 1,025 & 0,995 \\
$25 \mathrm{kHz}-3$, & 9,332 & 5,243 & 1,011 & 0,997 \\
$25 \mathrm{kHz}-10$, & 8,685 & 4,512 & 1,024 & 0,993 \\
$40 \mathrm{kHz}-3$, & 8,367 & 3,910 & 1,027 & 0,994 \\
$40 \mathrm{kHz}-10$, & 8,283 & 3,984 & 1,019 & 0,993 \\
\hline
\end{tabular}

A partir dos resultados apresentados na Tabela 1 é possível avaliar o efeito do banho ultrassônico sobre a difusividade efetiva $\left(D_{\text {eff }}\right)$ nas fatias jaca submetidas à liofilização. Com exceção do tratamento de $25 \mathrm{kHz}$ durante 3 minutos, cujo valor da difusividade efetiva aumentou, a utilização dos outros tratamentos diminuiu este parâmetro em relação ao Controle.

Como se trata de um produto natural, algumas variáveis, como a espessura tornam- se difíceis de controlar. A espessura tem forte influência na difusividade.

A partir dos valores médios das espessuras da jaca em cada tipo de tratamento apresentadas na Erro! Fonte de referência não encontrada. 1 , conclui-se que o alto valor de difusividade encontrado para a condição de $25 \mathrm{kHz}$ - 3', deve-se, também, ao fato de ser a maior espessura entre todos os tratamentos, o que justifica o maior valor da difusividade.

A Figura 3 mostra a razão de reidratação da jaca liofilizada em função do tempo. Os valores dessa razão variaram de 1 a 4,5; apresentando nos instantes iniciais o mais significativo aumento. Com o passar do tempo o aumento na razão de reidratação ocorreu de forma mais moderada.

Figura 3 - Razão de reidratação em função do tempo para a jaca, com a Equação de Weibull ajustada.

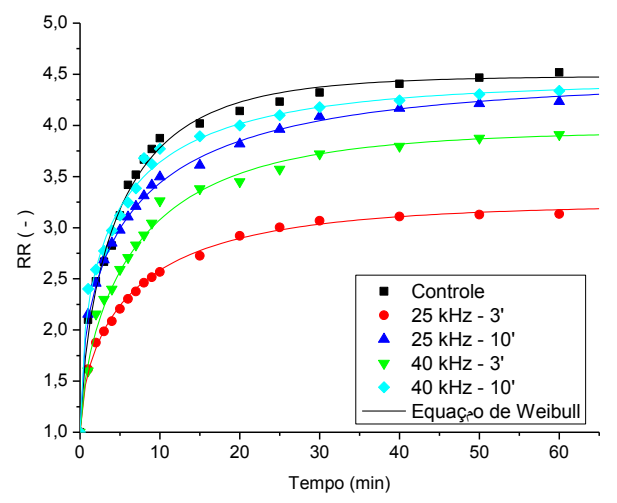

Ao se comparar as curvas de reidratação das amostras pré-tratadas e da amostra Controle, verifica-se um efeito negativo do uso do ultrassom. As amostras sonicadas apresentaram menores razões de reidratação durante todo o processo. Com o uso do ultrassom, aproximando as fibras e os poros da fruta, maior foi a dificuldade do produto em absorver água durante sua reidratação. Comparando-se somente os comportamentos de reidratação das amostras pré-tratadas, observa-se que, quanto maior o tempo de sonicação, maior a razão de reidratação que é 
alcançada para ambas as frequências estudadas.

$\mathrm{Na}$ Tabela 2 são apresentados os valores dos parâmetros estimados da Equação de Weibull, utilizada para descrever a cinética de reidratação da jaca liofilizada.

Tabela 2 - Parâmetros da Equação de Weibull

\begin{tabular}{lllll}
\hline \multicolumn{1}{c}{ Tratamento } & $\mathrm{RR}_{\mathrm{e}}(-)$ & $\alpha(-)$ & $\beta(\mathrm{min})$ & $\mathrm{R}^{2}$ \\
\hline Controle & 4,482 & 0,706 & 5,128 & 0,995 \\
$25 \mathrm{kHz}-3$, & 3,229 & 0,616 & 7,051 & 0,987 \\
$25 \mathrm{kHz}-10$, & 4,442 & 0,513 & 6,669 & 0,997 \\
$40 \mathrm{kHz}-3$, & 3,946 & 0,678 & 7,441 & 0,988 \\
$40 \mathrm{kHz}-10$, & 4,427 & 0,526 & 4,796 & 0,983 \\
\hline
\end{tabular}

Com base nos elevados valores obtidos para o coeficiente de determinação e conforme mostrado na Figura 3, verifica-se a boa concordância entre os dados experimentais e aqueles preditos pela equação de Weibull.

A análise da cinética de reidratação via equação de Weibull é de grande interesse, devido ao significado físico de seus parâmetros, fornecendo informações sobre ganho de $\mathrm{H}_{2} \mathrm{O}$, taxa de reidratação e razão de reidratação na saturação (MARQUES, 2008).

Os resultados reunidos Tabela indicam que quanto maior o tempo de tratamento, maior a razão de reidratação na saturação $\left(R_{\mathrm{e}}\right)$. No entanto, em comparação com a amostra-controle, os valores são menores, comprovando que não houve influência do ultrassom na reidratação.

Os valores de $\alpha$ indicam a velocidade de absorção de água no início do processo, com as cavidades próximas a superfície sendo preenchidas com água. Quanto menor o valor, maior a taxa de reidratação no início, explicando o fato de que a razão de reidratação atinge mais rapidamente o valor de saturação. Este fato pode ser comprovado fazendo a análise comparativa dos tratamentos, em ambas as frequências, a 10 minutos, com o Controle. Todos os três apresentam valores de saturação próximos. Como os valores de $\alpha$ para os tratamentos são menores, pode-se notar, através da Figura, uma maior inclinação de suas curvas, de modo que a tendência é que atinjam o valor de saturação mais rápido do que o Controle.

$\mathrm{O}$ inverso do parâmetro $\beta$ pode ser comparado com o coeficiente de difusão efetivo do modelo de difusão, sendo que, quanto menor o valor desse parâmetro, mais rapidamente a fruta absorve água, com os tratamentos realizados durante 3 minutos apresentando os maiores valores deste parâmetro. Este parâmetro representa a constante cinética da equação de Weibull, medindo o grau de dificuldade ou facilidade de reidratação do material (MARQUES, 2008).

$\mathrm{Na}$ Tabela 3 são apresentados os índices de reidratação de Lewicki:

Tabela 3 - Índices de Lewicki para a Jaca.

\begin{tabular}{llll}
\hline Tratamento & Índices & & \\
\cline { 2 - 4 } & CAA & $\mathrm{CRM}_{\mathrm{s}}$ & $\mathrm{CR}$ \\
\hline Controle & 0,835 & 0,897 & 0,749 \\
$25 \mathrm{kHz}-3$, & 0,721 & 0,775 & 0,572 \\
$25 \mathrm{kHz}-10$, & 0,796 & 0,797 & 0,641 \\
$40 \mathrm{kHz}-3$, & 0,822 & 0,809 & 0,670 \\
$40 \mathrm{kHz}-10$, & 0,809 & 0,770 & 0,623 \\
\hline
\end{tabular}

Ao se analisar os índices de Lewick obtidos para a jaca, conclui-se que a utilização do banho ultrassônico não melhorou a capacidade de absorção de água do produto, tampouco sua capacidade de reter sólidos solúveis. Constata-se também que não foi obtida uma completa reidratação das amostras, pois estas não atingiram o teor de umidade da fruta "in natura", com tais amostras atingindo valores entre 72 e $83 \%$ da quantidade de água perdida durante a secagem. Porém, ao comparar resultados obtidos por Marques (2008), nota-se que a capacidade da jaca em absorver água é superior a frutas, tais como abacaxi, manga, acerola e papaya.

O índice C.R.Ms. variou entre 77 e 90\%, e comparando-se, também, com os resultados obtidos por Marques (2008), verifica-se que tal índice, para a jaca, é superior a frutas como acerola, abacaxi, manga e papaya. Como o tecido do gomo da jaca é mais resistente, fato 
que pode ser percebido pela simples comparação pelo tato, evidencia-se que tal fruta é capaz de reter sólidos solúveis durante a reidratação de maneira melhor do que as frutas acima citadas.

Com a multiplicação desses dois índices (C.A.A. e C.R.M. .), têm-se os efeitos combinados dos processos de secagem e reidratação sobre a qualidade do produto sendo que o Controle apresentou a maior capacidade de reidratação. Presume-se que a utilização do ultrassom danifique parte da estrutura da fruta.

As Figuras 4 (a) a 4 (e) mostram os valores dos parâmetros colorimétricos dos frutículos de jaca.

Figura 4 - Parâmetros colorimétricos $\left(\mathrm{L}^{*}, \mathrm{a}^{*} \mathrm{e} \mathrm{b}\right)$ da jaca antes e após a liofilização. Controle (a), 25 kHz-3' (b), 25 kHz-10' (c), 40 kHz-3' (d) e 40 kHz$10^{\prime}(\mathrm{e})$.

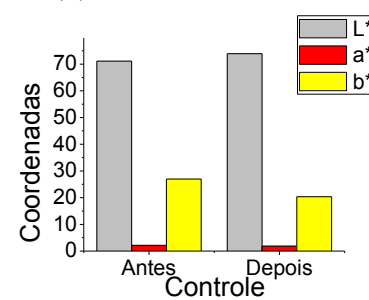

(a)

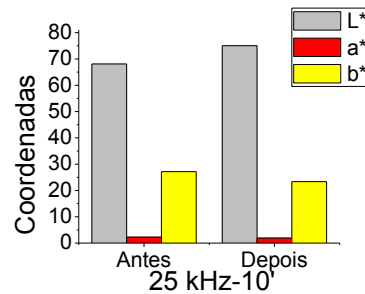

(c)

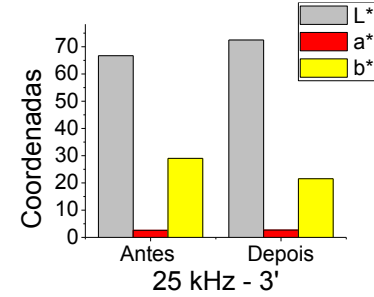

(b)

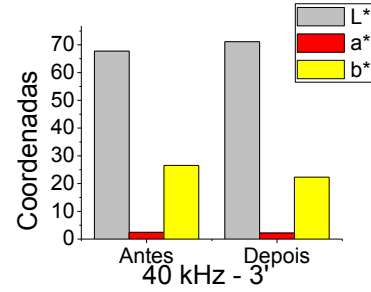

(d)

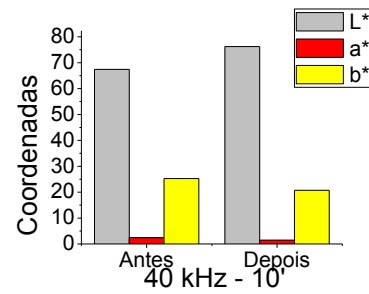

(e)

Nota-se que a utilização dos prétratamentos não influenciou nos parâmetros colorimétricos do produto liofilizado, já que não houve diferença significativa entre os valores apresentados pelas amostras controle e sonicadas. A pequena variação nos valores evidencia a estabilidade dos parâmetros colorimétricos devido ao uso da liofilização como processo de secagem (MARQUES, 2008).

Observou-se que, após a liofilização, houve, para todos os casos, uma redução no parâmetro $b^{*}$. A variação do parâmetro $a^{*}$ foi mínima para todos os casos, e, pelos valores apresentados, em torno de 1,5 a 3, indica que é uma cor neutra, como o branco, o cinza ou o preto; o que indica a quase inexistência dessa pigmentação na jaca, predominando o parâmetro $b^{*}$, que, sendo positivo, indica a coloração amarelada da fruta. $\mathrm{O}$ parâmetro $\mathrm{L}^{*}$, que indica a luminosidade, aumentou para as frutas liofilizadas em todos os tratamentos.

Este aumento da coordenada $\mathrm{L}^{*}$ apresenta um resultado satisfatório, devido ao fato do produto final ter sua luminosidade aumentada. Este é um atrativo comercial, já que os consumidores se interessam mais por produtos vistosos, com a cor chamativa.

As Figuras 5(a) a 5(e) apresentam a variação dos parâmetros hue e croma dos frutículos de jaca.

A partir dos resultados mostrados na Figura, evidencia-se a estabilidade da coordenada hue, que indica uma diferença de tonalidade. Não houve uma expressiva alteração nesse parâmetro no decorrer do processo. Este fato é um indício muito bom, porque implica que a fruta manteve, quase que totalmente, sua coloração natural, o que torna o produto bem aceito no mercado.

Em todos os tratamentos, houve um decaimento na coordenada croma, o que indica perda de intensidade. Tal fato pode ser entendido, observando o "clareamento" do fruto da jaqueira. Esse "clareamento" pode ser comprovado também pela visualização, na Figura, do parâmetro $b^{*}$, que teve seu valor reduzido em todos os casos, indicando perda de coloração amarela. 
Figura 5 - Tonalidade (hue) e intensidade (croma) dos frutículos de jaca, antes e após a liofilização. Controle (a), 25 kHz-3' (b), $25 \mathrm{kHz}-10$ ' (c), $40 \mathrm{kHz}-$ $3^{\prime}$ (d) e 40 kHz-10' (e).

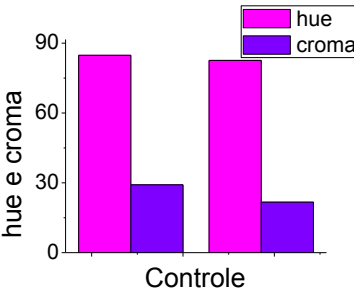

(a)

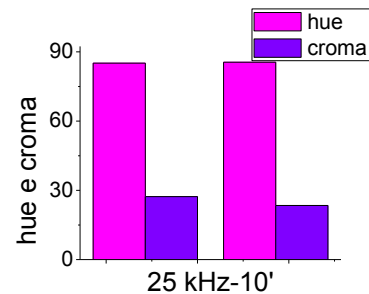

(c)

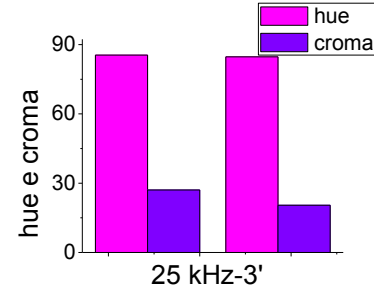

(b)

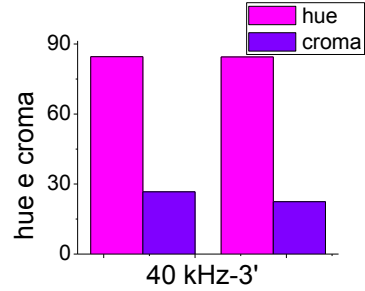

(d)

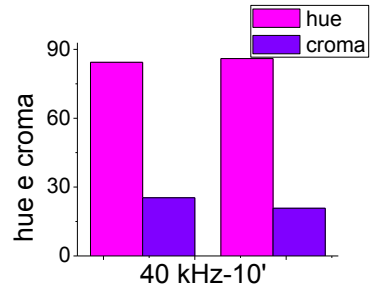

(e)

O $\beta$-caroteno é um pigmento de coloração amarela (RODRIGUEZ-AMAYA, 2001). Em processos de desidratação da jaca, verifica-se que há a perda desse composto bioativo (OLIVEIRA, GODOY e BORGES, 2010). A diminuição do parâmetro croma e do parâmetro $b^{*}$ pode ser explicada pela perda de parte desse composto no processo de liofilização.

\section{CONCLUSÕES}

A partir dos resultados obtidos no presente trabalho conclui-se que as cinéticas de secagem, com e sem pré-tratamento ultrassônico, foram adequadamente representadas pelo modelo difusivo.

A influência do pré-tratamento ultrassônico sobre a transferência de massa na liofilização foi analisada em termos da difusividade mássica efetiva. A aplicação da sonicação levou a uma redução de 8 a $16 \%$ na difusividade efetiva da jaca e, consequentemente, a um aumento no tempo do processo de secagem. Isto devido a possíveis modificações estruturais no material causadas pelas ondas ultrassônicas.

A sonicação dos frutículos de jaca antes do processo de liofilização não melhorou, como esperado, as propriedades de reidratação do produto. As amostras pré-tratadas além de apresentarem uma menor capacidade de absorver água durante a reidratação, comparadas à amostra controle, tiveram uma menor retenção de sólidos solúveis.

Não houve variação significativa nos parâmetros colorimétricos $\mathrm{a}^{*} \mathrm{e} \mathrm{b}^{*}$, indicando a preservação da cor da jaca durante o processo de liofilização. Ademais, a luminosidade dos frutículos de jaca, sonicados ou não, foi melhorada após a secagem, conforme evidenciado pelo aumento dos valores de $\mathrm{L}^{*}$.

\section{NOMENCLATURA}

$\begin{array}{llr}\text { C.A.A. } & \begin{array}{l}\text { Capacidade } \\ \text { absorção de água }\end{array} \\ \text { C.R. } & \begin{array}{l}\text { Capacidade } \\ \text { reidratação }\end{array} \\ \text { Capacidade } & \text { de } \\ \text { C.R.M.s } & \begin{array}{l}\text { retenção } \\ \text { massa seca }\end{array} & \text { de } \\ & \text { Pureza } & \text { ou }\end{array}$

$D_{\text {eff }} \quad$ Difusividade

efetiva

Mudança de

\begin{tabular}{|c|c|}
\hline Hue & $\begin{array}{l}\text { Mudança } \\
\text { coloração }\end{array}$ \\
\hline $\begin{array}{l}\mathrm{L}, \mathrm{a}^{*} \mathrm{e} \\
\mathrm{b}^{*}\end{array}$ & $\begin{array}{l}\text { Parâmetros } \\
\text { colorimétricos }\end{array}$ \\
\hline $\mathrm{L}_{\mathrm{c}}$ & $\begin{array}{l}\text { Comprimento } \\
\text { característico }\end{array}$ \\
\hline $\mathrm{m}(\mathrm{t})$ & $\begin{array}{ll}\text { Massa } & \text { um } \\
\text { instante (t) } & \end{array}$ \\
\hline $\mathrm{m}_{\mathrm{ss}}$ & $\begin{array}{l}\text { Massa de sólido } \\
\text { seco }\end{array}$ \\
\hline
\end{tabular}




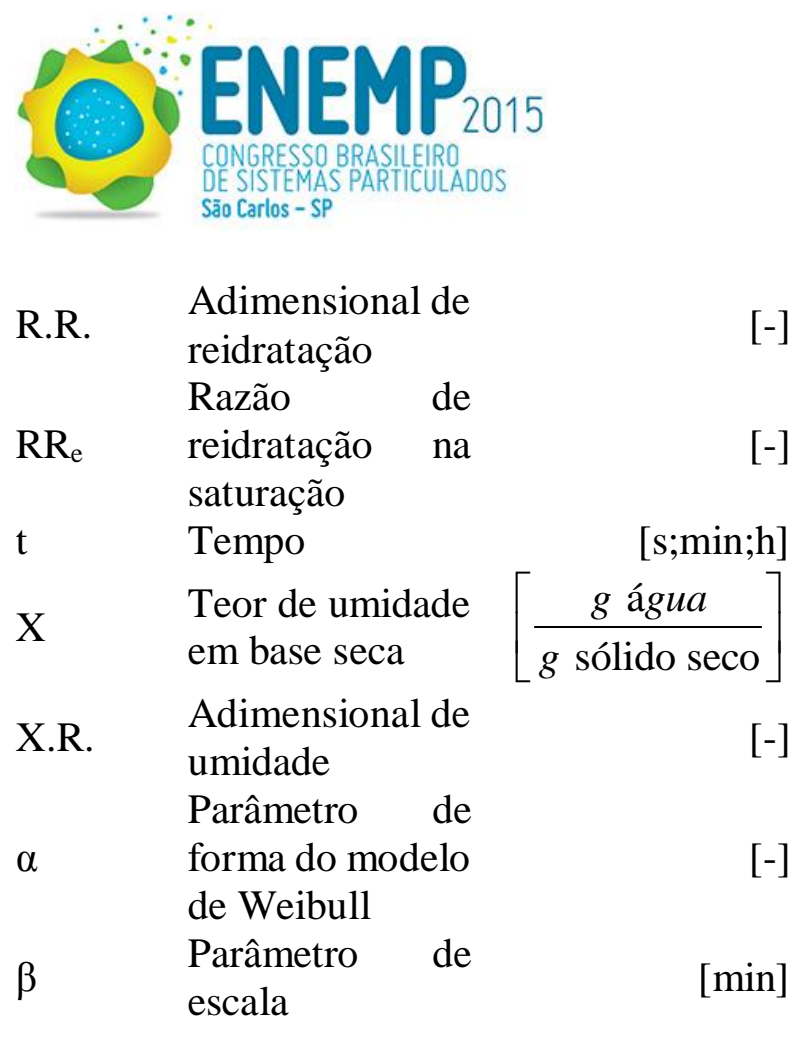

\section{REFERÊNCIAS}

CHUNTHAWORN, S; ACHARIYAVIRIYA, S.; ACHARIYAVIRIYA, A; NAMSANGUAN, K. Color kinetics of longan flesh drying at high temperature. Procedia Engineering, v32, p. 104-111, 2012.

DUARTE, M. E. M.; UGULINO, S. M. P.; MATA, M. E. R. M. C.; GOUVEIA, D. S.; QUEIROZ, A. J. M.. Desidratação osmótica de fatias de jaca. Revista Ciência Agronômica, Fortaleza, v. 43, p. 478-483, 2012.

FISSORE, D.; PISANO, R.; BARRESI, A. A. Applying quality-by-design to develop a coffee freeze-drying process. Journal of Food Engineering, v 123, p. 179-187, 2013.

INSTITUTO ADOLFO LUTZ. Normas Analíticas do Instituto Adolfo Lutz. v. 1: Métodos químicos e físicos para análise de alimentos, 3. ed. São Paulo: IMESP, 1985. p. 23-5.

MARQUES, L. G. Liofilização de Frutas Tropicais. Tese (Doutorado em Engenharia Química)-Programa de Pós-Graduação em Engenharia Química, Universidade Federal de São Carlos. São Carlos-SP, p. 293. 2008.
[-] MASON, T. J. Power ultrasound in food processing - the way forward. Thomson Science., London, UK, p. 105-126, 1998.

OLIVEIRA, F. D.; GODOY, L. D. O.; BORGES,. Desenvolvimento tecnológico de jaca (Artocarpus heterophyllus, Lam.) desidratada., Fortaleza, 2009.

OLIVEIRA, L. F. D.; GODOY, R. L. D. O.; BORGES, S. V. Estudo da qualidade nutricional de jaca (Artocarpus heterophyllus, Lam.) in natura e desidratada sob diferentes condições de secagem. EMBRAPA, 2010.

RODRIGUEZ-AMAYA, D. B. A guide to carotenoid analysis in foods. $1^{\mathrm{a}}$. ed. Washington: ILSI Press, 2001.

SANTOS, J. T. S.; COSTA, F. S. C.; SOARES, D. S. C.; CAMPOS, A. F. P.; CARNELOSSI, M. A. G.; NUNES, T. P.; JÚNIOR, A. M. O.. Avaliação de mangaba liofilizada através de parâmetros físicoquímicos. Scientia Plena, São Cristóvão-Se, v 8, n 2004, p. 1-5, 2012.

SILVA, A.; TREVISANI, B.; BARGHINI, L. T.; WOOTEN, S.. Sabores da Cozinha Contemporânea. $\quad 1^{\mathrm{a}}$. ed. $\quad$ [S.1.]: Melhoramentos, v. I, 2005.

\section{AGRADECIMENTOS}

Os autores agradecem à CAPES e COPES/UFS pelo auxílio financeiro. 